\title{
Internal Hemorrhoids Coexisting with Chronic Anal Fissure: New Nonsurgical Modalities
}

Botulinum toxin A (BTA) can be used in the treatment of chronic anal fissure by injection into the internal or external sphincter $(1,2)$. BTA reliably relieves sphincter spasm, and sphincter relaxation promotes healing by increasing the blood flow through the posterior anal artery (3). The mean minimum basal pressure in patients suffering from hemorrhoids or chronic anal fissure is significantly higher than in healthy individuals (4). It can be assumed that prolapsing hemorrhoids may obstruct healing, as they create an extra volume (in addition to feces) dilating the anal sphincters. We report here two cases in which BTA injection was combined with ligation.

Case 1. During anoscopy, a 31-year-old man received three injections, each of $5 \mathrm{U}$ $(0.1 \mathrm{ml})$ BTA (Botox). Two of the injection sites were located laterally in the proximal part, and the third one was in the distal part of the fissure. After chronic fissure healing (in the sixth week after BTA administration), while relaxation of the anal sphincters was still effective, rubber-band ligation of part of the hemorrhoid was carried out (Figure 1). Next, liquid cryotherapy was applied $\left(-194^{\circ} \mathrm{C}\right)$. Since it was not possible to insert a speculum ( $2.4 \mathrm{~cm}$ diameter) into the anal canal, BTA was again administered five weeks later. Similar nonsurgical treatment of the other hemorrhoids was then possible two, seven, and 12 weeks later.

Case 2. A 67-year-old woman received BTA injection, and two weeks later, nonsurgical treatment of hemorrhoids was carried out before the healed chronic anal fissure. Instrumental hemorrhoid treatment was carried out three times (at four-week to five-week intervals).
At the end of treatment, scar tissue was found over the healed fissures and firstdegree hemorrhoids in both patients (Figure 2). Five months later, the patients had no signs of fissure and no symptoms of hemorrhoids. This pharmacological form of sphincterotomy and instrumental treatment of hemorrhoids allowed these patients to avoid general anesthesia and surgical treatment, with its associated complications (5).

M. Madaliñski', M. Labon' ${ }^{2}$ Z. Adrich',

A. Kryszewski ${ }^{3}$

'Dept. of Internal Medicine II

${ }^{2}$ Gastroenterology Service,

St. Wojciech-Adalbertus Hospital, Gdansk, Poland

${ }^{3}$ Dept. of Gastroenterology,

Medical University of Gdansk, Poland

\section{References}

1. Maria G, Cassetta E, Gui D, et al. A comparison of botulinum toxin and saline for the treatment of chronic anal fissure. N Engl J Med 1998; 4: 217 20.

2. Jost WH. One hundred cases of anal fissure treated with botulin toxin: early and long-term results. Dis Colon Rectum 1997; 40: 1029-32.

3. Lund JN, Scholefield JH. Aetiology and treatment of anal fissure. Br J Surg 1996; 93: 1335-44.

4. Farouk R, Duthie GS, MacGregor AB, et al. Sustained internal sphincter hypertonia in patients with chronic anal fissure. Dis Colon Rectum 1994; 37: $424-9$

5. Oh C, Divino CK Steinhagen RM. Anal fissure: 20-year experience. Dis Colon Rectum 1995; 38: 378-82.

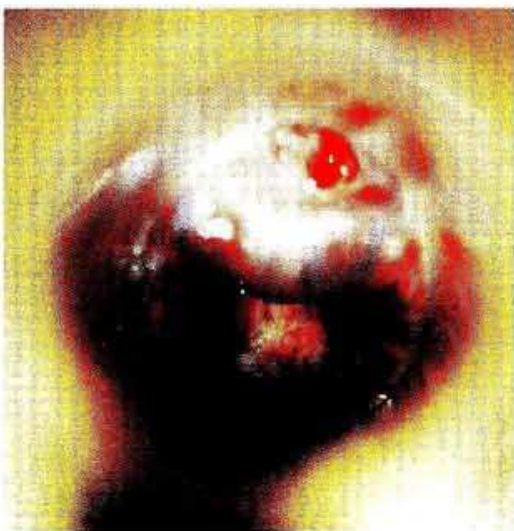

Figure 1: A hemorrhoid after rubber-band ligation and liquid nitrogen cryotherapy before healing of the chronic anal fissure (two weeks after BTA administration),

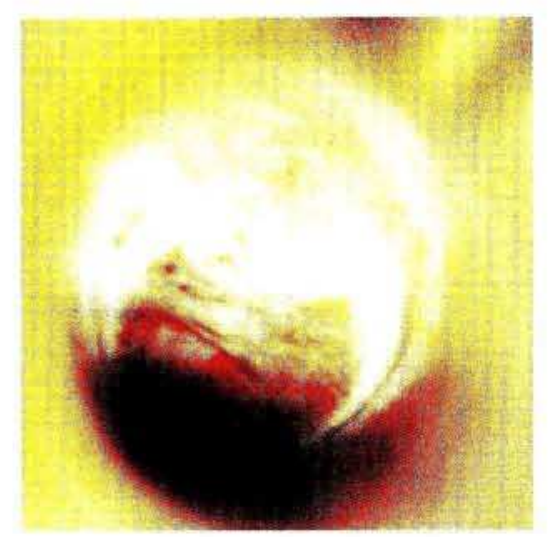

Figure 2: One of the scars seen represents the healed fissure, and the other followed instrumental hemorrhoid treatment.

Corresponding Author

M. Madaliñski, M.D.

ul. Kosciuszki 101/7

80-421 Gdansk

Poland

Fax: + 48-58-3469972 